\title{
Down-Regulated MAC30 Expression Inhibits Proliferation and Mobility of Human Gastric Cancer Cells
}

\author{
Xiao-Yan Xu Li-Juan Zhang $^{\mathrm{b}}$ Yan-Qiu Yu ${ }^{\mathrm{a}}$ Xiao-Tong Zhang ${ }^{c}$ Wan-jing Huang ${ }^{c}$ \\ Xiao-Cui Nied Guo-Qing Songe \\ aDepartment of Pathophysiology, College of Basic Medicine, China Medical University, ${ }^{\mathrm{b} D e p a r t m e n t}$ of \\ Obstetrics and Gynecology, Shengjing Hospital of China Medical University, 'China Medical University \\ Clinical Medicine seven-year, ${ }^{\mathrm{d} M a t e r n i t y}$ and Infant Hospital Shenyang, ${ }^{\mathrm{e} D e p a r t m e n t}$ of Pancreatic and \\ Breast Surgery, Shengjing Hospital of China Medical University, Shenyang, Liaoning, People's Republic \\ of China
}

\section{Key Words}

MAC30 • Gastric carcinoma $•$ Lampodia $・$ Invasion

\begin{abstract}
Background: Gastric cancer is one of the most common cancers in the world. MAC30/ Transmembrane protein 97 (TMEM97) is aberrantly up-regulated in many human carcinoma cells. However, the function of MAC30 in gastric carcinoma cells is not studied. Material and Methods: To investigate the function of MAC30 in gastric carcinoma, we used RNA silencing technology to knock down the expression of MAC30 in gastric cancer cells BGC-823 and AGS. Real-time quantitative PCR and Western blot were used to analyze the mRNA level and the related protein expression. The localization of MAC30 and lamellipodia was observed by immunofluorescence. The biological phenotypes of gastric cells were examined by cell proliferation assay, cell cycle analysis, apoptosis assay, cell migration and invasion assay. Results: We found that down-regulation of MAC30 expression efficiently inhibited the proliferation of gastric cancer cells. Furthermore, the mobility of gastric cancer cells was also inhibited by down-regulation of MAC30. Moreover, we found that MAC30 knockdown inhibited AKT phosphorylation and reduced the expression of cyclinB1 and WAVE2. Conclusion: To our knowledge, this is the first report investigating the effect of MAC30 on growth, cell cycle, migration, and invasion in gastric carcinoma cells via suppressing AKT signaling pathway. MAC30 may be a potential therapeutic target for treatment of gastric carcinoma.
\end{abstract}




\section{Introduction}

Gastric cancer is ranked as the fourth most common and the second most frequent cause of death from cancer [1]. Tumorigenesis and progression of gastric carcinoma is a multistage and multifactorial process, and hence increased understanding of changes in gene expression during carcinogenesis, particularly identification of novel biomarkers for cancer diagnosis and novel therapeutic targets will improve the diagnosis, treatment and prevention.

Transmembrane protein 97 (TMEM97), also known as MAC30 is located on 17q11.2. The human TMEM97 cDNA encodes a conserved integral membrane protein of 176 amino acids, including five topological domains and four transmembrane domains [2]. The high levels of MAC30 were observed in breast, esophagus, stomach and colon cancer in contrast to the low levels observed in pancreatic and renal cancer [3]. The distinct expression of MAC30 determines its distinct roles in human malignancies. MAC30 as a conserved integral membrane protein plays a role in controlling cellular cholesterol levels [4]. Another finding suggests that MAC30 are a downstream target of progesterone (P4) in normal ovarian surface epithelial cells and that MAC30 plays a role in cholesterol and lipid metabolism [5]. As a non-erythropoietic gene, MAC30 mRNA is expressed in the fetal liver, but not in the adult liver, suggesting a possible role in growth and differentiation of liver [6].

Several lines of evidence suggest that MAC30 expression in metastasis was an indicator for poor survival of rectal cancer patients. After radiotherapy, MAC30 seemed to be more related to aggressive morphological and biological factors expression such as PRL (phosphatase of regenerating liver) and Ki-67 [7]. The cytoplasmic expression of MAC30 was much stronger in lymph node metastasis compared to primary tumor and normal mucosa, and was related to the survival rate of the patient with colorectal cancer [8]. Elevated expression of MAC30 predicts lymph node metastasis and unfavorable prognosis in the patients with epithelial ovarian cancer [9]. Overexpression of MAC30 is associated with poor clinical outcome in human non-small-cell lung cancer [10], and predicts nodal metastasis and poor differentiation in oral squamous cell carcinoma [11].

H. Kayed et al. [3] analyzed the levels of MAC30 mRNA and protein in normal and cancerous tissue samples of the stomach through quantitative RT-PCR, in situ hybridization and immunohistochemistry. They found that MAC30 protein was localized in normal gastric tissues, especially in the mucosal cells, and gastric tumors displayed strong MAC30 immunoreactivity in the cancer cells [3]. However, the biological role of MAC30 in the progress of gastric cancer is unknown.

In the present study, we investigated the effects of down-regulated MAC30 expression on the proliferation, cell cycle, apoptosis, mobility of gastric carcinoma cells, and explored the underlying molecular mechanisms.

\section{Materials and Methods}

\section{Cell culture}

Gastric carcinoma cell lines (BGC-823, MGC-803, SGC-7901, MKN45, AGS, MKN28 and KATO-III), gastric epithelial cell line (GES-1) were purchased from Japanese Physical and Chemical Institute, Tokyo, Japan and Beijing Institute for Cancer Research, Beijing, China and Cell bank of Chinese Academy of Sciences, Shanghai, China, respectively. They were maintained in RPMI 1640 or Ham F12 medium supplemented with 10\% fetal bovine serum (FBS), 100 units $/ \mathrm{ml}$ penicillin, and $100 \mu \mathrm{g} / \mathrm{ml}$ streptomycin, in a humidified atmosphere of $5 \% \mathrm{CO}_{2}$ at $37^{\circ} \mathrm{C}$.

\section{Transfection}

BGC-823 and AGS cells were transfected with siRNAs to silence MAC30 expression at $72 \mathrm{~h}$ after seeding on dishes according to the manufacturer's instructions (QIAGEN, Valencia, CA, USA). The target TMEM97 


\begin{tabular}{|c|c|c|}
\hline Cellular P & Cell Physiol Biochem 2014;33:1359-1368 & \\
\hline and Biochemistry & $\begin{array}{l}\text { DOI: } 10.1159 / 000358703 \\
\text { Published online: Tvlay 05, } 2014\end{array}$ & $\begin{array}{l}\text { (c) } 2014 \text { S. Karger AG, Basel } \\
\text { www.karger.com/cpb }\end{array}$ \\
\hline
\end{tabular}

Table 1. Primers used in the present study. AT: annealing temperature

\begin{tabular}{|c|c|c|c|c|c|}
\hline Names & Primer's sequence & Distribution & $\begin{array}{l}\mathrm{AT} \\
\left({ }^{\circ} \mathrm{C}\right) \\
\end{array}$ & $\begin{array}{l}\text { Product } \\
\text { size(bp) }\end{array}$ & $\begin{array}{c}\text { Extension } \\
\text { time }(\mathrm{s})\end{array}$ \\
\hline МАСЗО & $\begin{array}{l}\text { F: 5'- CTCAGCCACATCCCC -3' } \\
\text { R: 5'- CACAAGCTCGCAAAAC -3' }\end{array}$ & $\begin{array}{l}\text { NM_014573.2 } \\
200-370\end{array}$ & 60 & 171 & 34 \\
\hline GAPDH & $\begin{array}{l}\text { F: 5'-CAATGACCCCTTCATTGACC-3' } \\
\text { R: 5'-TGGAAGATGGTGATGGGATT-3' }\end{array}$ & $\begin{array}{l}\text { NM_002046.4 } \\
273-407\end{array}$ & 60 & 135 & 34 \\
\hline
\end{tabular}

sequences were GAAGCUGCUGCUAAAGCAUUU (sense) and AUGCUUUAGCAGCAGCUUCUU (anti sense). The negative siRNA control was purchased from Santa Cruz.

\section{Real-time Quantitative PCR (qPCR)}

Total RNA was extracted from gastric carcinoma cell using QIAGEN RNeasy mini kit (QIAGEN). Two micrograms of total RNA were subjected to CDNA synthesis using AMV transcriptase and random primer (Takara). Real-time PCR was performed according to the protocol of SYBR Premix Ex Taq ${ }^{\mathrm{TM}}$ II kit. Specific primer pairs in the experiment were listed in Table 1.

\section{Western blot}

Denatured protein was separated on a 10\% SDS-polyacrylamide gel and transferred to Hybond membrane (Amersham Biosciences, Westborough, MA, USA), which was then blocked overnight in 5\% skim milk in Tris buffered saline with Tween20 (TBST). For immunobloting, the membrane was incubated for overnight at $4^{\circ} \mathrm{C}$ with the rabbit anti-MAC30 (Novus Biotechnology, Littleton, CO, USA, 1:500), rabbit antiAKT antibody (Santa Cruz Biotechnology, Santa Cruz, CA, USA, 1:500), rabbit anti-P-AKT(Ser 473) antibody (Santa Cruz, 1:500), rabbit anti-P-AKT(Thr 308) antibody (Santa Cruz, 1:500), mouse anti-cyclin B1 antibody (Santa Cruz, 1:250), rabbit anti-WAVE2 antibody (Santa Cruz, 1:500), and rabbit anti-MMP2 antibody (Santa Cruz, 1:500). Then, it was rinsed by TBST and incubated with anti-rabbit or anti-mouse IgG conjugated to horseradish peroxidase (DAKO, Glostrup, Denmark, 1:1000) for 2 hours. Bands were visualized by ECL-Plus detection reagents (Amersham). After that, the membrane was washed with WB Stripping Solution (Pierce, Rockford, IL, USA) for 15 minutes and treated as described above except mouse anti- $\beta$-actin antibody (Santa Cruz, 1:1000) as an internal control.

\section{Immunofluorescence}

Cells were grown on glass coverslips and fixed with PBS containing $4 \%$ formaldehyde for $10 \mathrm{~min}$, and permeabilized with $0.2 \%$ Triton X-100 in PBS for 10 min at room temperature. After washing with PBS, cells were incubated overnight at $4^{\circ} \mathrm{C}$ with rabbit anti-MAC30 (Novus Biotechnology, 1:100). The anti-rabbit Alexa Fluor ${ }^{8} 488$ IgG (Invitrogen) was used as secondary antibody. Phalloidin conjugates TRITC (Sigma, Louis, MO, USA) was employed to observe the lamellipodia. Nuclei were stained with $1 \mu \mathrm{g} / \mathrm{ml}$ DAPI (Sigma) for $15 \mathrm{~min}$ at $37^{\circ} \mathrm{C}$. Finally, coverslips were mounted with SlowFade ${ }^{\circledR}$ Gold antifade reagent (Invitrogen) and observed under a laser confocal microscope (Olympus).

\section{Cell proliferation assay}

Cell proliferation was assessed by the cell counting kit-8 (CCK-8) assay according to the manufacturer's protocol (Dojindo Laboratories, Gaithersburg, MD, USA). In brief, $2 \times 10^{3}$ cells/well were seeded on 96-well plate and allowed to adhere at $37^{\circ} \mathrm{C}, 5 \% \mathrm{CO}_{2}$. At different time points, $10 \mu \mathrm{l}$ of CCK-8 solution was added into each well of the plate and the plates were incubated for $2 \mathrm{~h}$ in the incubator, then measured at $450 \mathrm{~nm}$ using the Tecan Infinite 2000 Microplate Reader.

\section{Cell cycle analysis}

$1 \times 10^{6}$ cells were collected, washed by PBS twice and fixed in cold $10 \mathrm{ml}$ ethanol for more than $2 \mathrm{~h}$ at $4^{\circ} \mathrm{C}$. And then, cells were washed by PBS twice and incubated with RNase at $37^{\circ} \mathrm{C}$ for $1 \mathrm{~h}$. The tube with cells was added by PI to $50 \mu \mathrm{g} / \mathrm{ml}$ and incubated at $4^{\circ} \mathrm{C}$ in the dark for $30 \mathrm{~min}$. Finally, FACS was employed to examine the PI signal (BD Biosciences, Baltimore, MD, USA). 
Fig. 1. Expression of MAC30 gene in gastric carcinoma cell lines and gastric epithelial cell line. (A) MAC30 mRNA was detectable at different level in gastric carcinoma cell lines (MGC-803, BGC-823, MKN45, SGC-7901, AGS, MKN28, and KATO-III) and gastric epithelial cell line (GES-1). (B) Cell lysate was loaded and probed with anti-MAC30 antibody $(24 \mathrm{kDa})$ with $\beta$-actin (42 $\mathrm{kDa}$ ) as an internal control. MAC30 protein expression was comparatively higher in BGC-823 and AGS cells than other cell lines $L^{*}, p$ $<0.05$ ). Results are representative of three different experiments and data are expressed as mean $\pm \mathrm{SE}$.

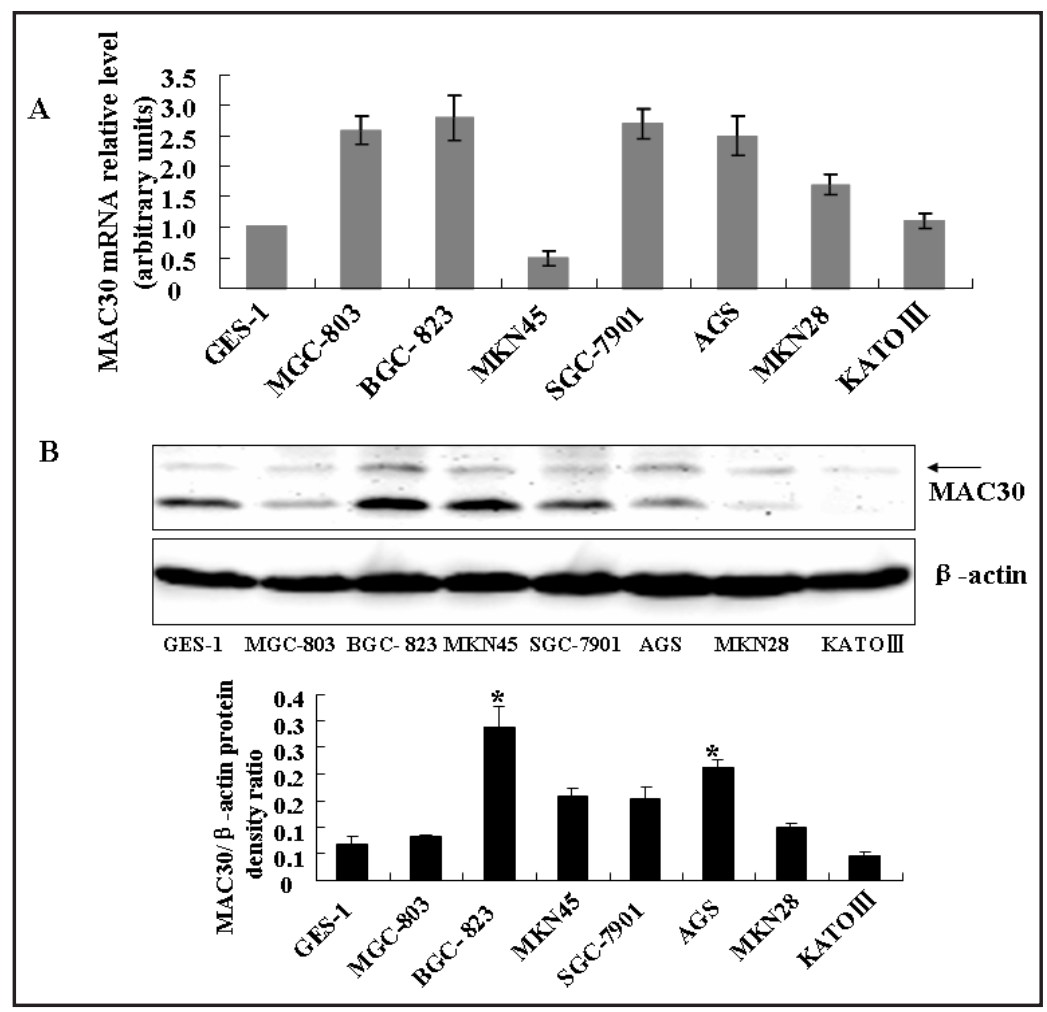

\section{Apoptosis assay}

Flow cytometry was performed with Propidium Iodide (PI) and fluorescein isothiocyanate (FITC) - labeled Annexin V (KeyGEN Biotech, Nanjing, China) to detect phosphatidylserine externalization as an endpoint indicator of early apoptosis. Annexin $\mathrm{V}$ is a calcium-dependent phospholipid- binding protein that has a high affinity for the membrane phospholipid phosphatidylserine (PS), and is useful for identifying apoptotic cells with exposed PS [12]. PI is used to distinguish viable from nonviable cells. In brief, cells were washed twice with cold PBS, resuspended in $500 \mu \mathrm{l} 1 \mathrm{x}$ Binding Buffer at a concentration of $1 \times 10^{6}$ cells/ $\mathrm{ml}$, and incubated with $5 \mu \mathrm{l} \mathrm{FITC-} \mathrm{Annexin} \mathrm{V} \mathrm{and} 5 \mu \mathrm{l}$ PI. Samples were gently vortexed and incubated for $15 \mathrm{~min}$ at $25^{\circ} \mathrm{C}$ in the dark. Flow cytometry was performed within 1 hour by a FACScan flow cytometer (BD Biosciences).

\section{Cell migration and invasion assays}

For migration assay, $2.5 \times 10^{5}$ cells were resuspended in serum-free RPMI 1640, and seeded in the control-membrane insert on the top portion of the chamber (BD Bioscience). The lower compartment of the chamber contained $10 \%$ FBS as a chemo- attractant. After incubated for $24 \mathrm{~h}$, cells on the membrane were scrubbed, washed with PBS and fixed in 100\% methanol and stained with Giemsa dye. For invasive assay, the procedures were the same as above excluding the matrigel-coated insert (BD Bioscience). Images were visualized with a laser confocal microscope (Olympus).

\section{Statistical Analysis}

Statistical evaluation was performed using Fisher's exact test to compare the different rates. SPSS 13.0 software was applied to analyze all data and $p<0.05$ was considered statistically significant.

\section{Results}

The expression of MAC30 in gastric carcinoma cells

To investigate the MAC30 transcription profile in gastric carcinoma cells, a quantitative real-time RT-PCR (q-RT-PCR) was employed. With primers specific to MAC30 gene, q-RT-PCR 

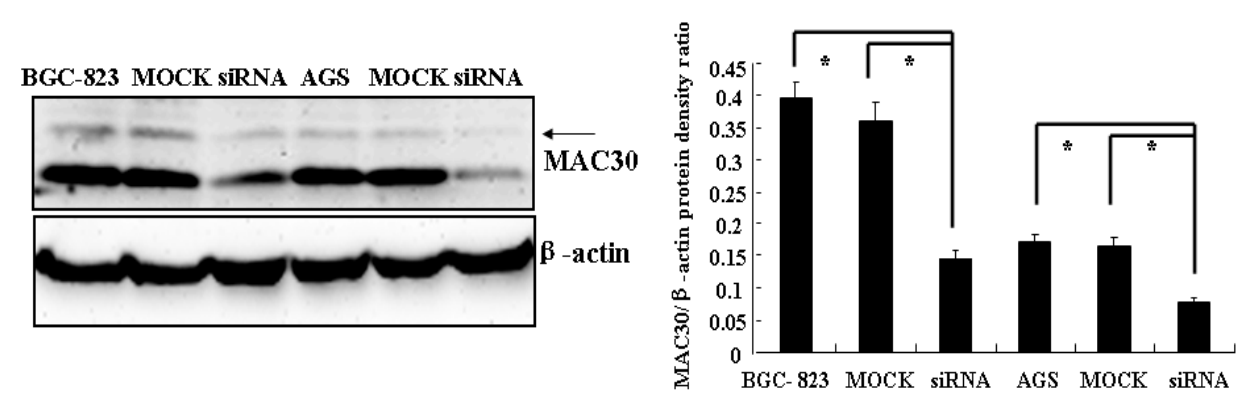

Fig. 2. After transfection of MAC30 siRNA, MAC30 expression was reduced in BGC-823 and AGS cells by western blot. Results are representative of three different experiments and data are expressed as mean \pm SE.

Fig. 3. MAC30 siRNA transfectants showed a lower growth in comparison with control $(*, p<0.05)$ by the cell counting kit-8 (CCK-8) assay. (A) MOCK: BGC-823 transfected with control siRNA; MAC30 siRNA: BGC-823 transfected with MAC30 siRNA. (B) MOCK: AGS transfected with control siRNA; MAC30 siRNA: AGS transfected with MAC30 siRNA. Results are representative of three different experiments and data are expressed as mean \pm SE.

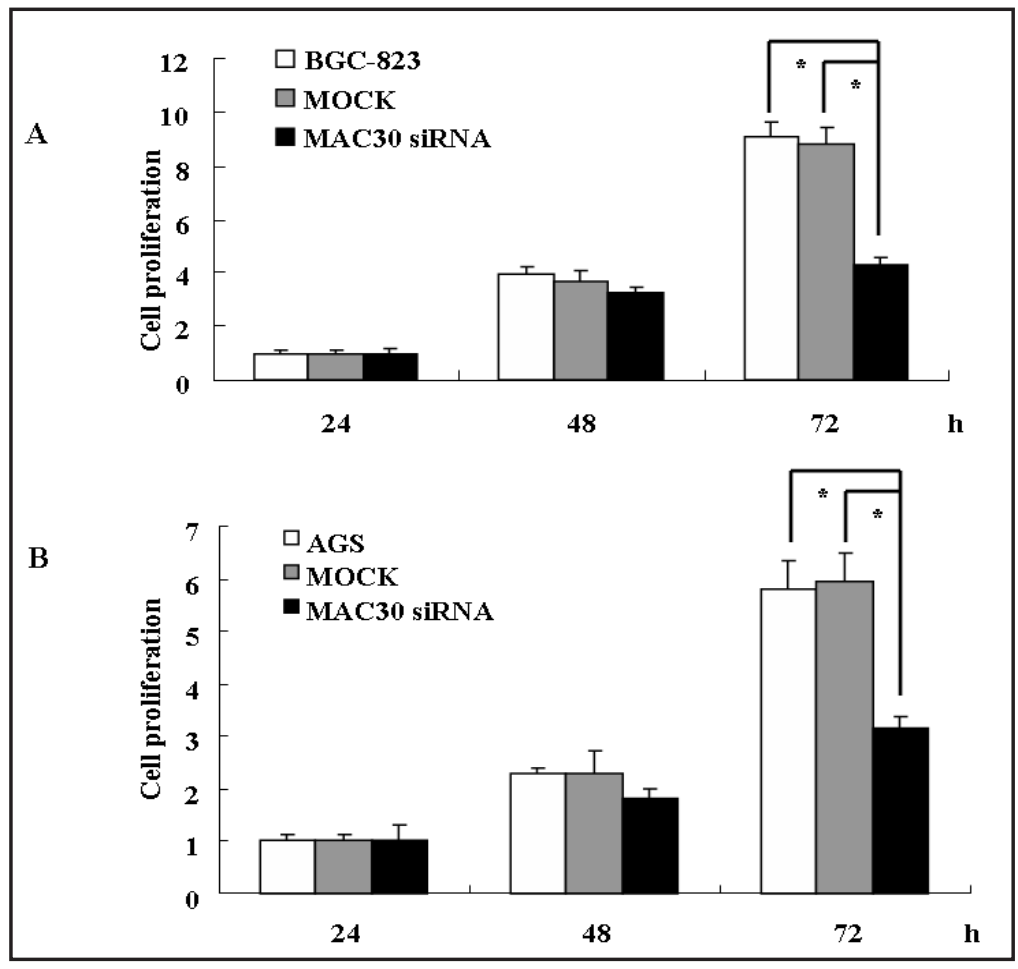

reveals the transcription of MAC30 in cells, and MAC30 transcription was found at different level in various gastric carcinoma cell lines (Fig. 1A). Among the cells, MAC30 protein expression was found at a comparatively higher in BGC-823 and AGS cells $(p<0.05$, Fig. 1B).

The effects of MAC30 knockdown on biological phenotypes of BGC-823 and AGS

Optimal MAC30 gene knockdown conditions were determined by dose-response and time course transfections in BGC-823 and AGS cells. Western blot analysis showed the most effective knockdown condition (80\%) was 150 nM MAC30 siRNA for 72 h (Fig. 2). Similar effects on MAC30 protein expression were shown by Immunofluorescence (Fig. 5).

MAC30 knockdown could inhibit cellular proliferation ( $p<0.05$, Fig. 3), migration and invasion ( $p<0.05$, Fig. 4), and cause weaker lamellipodia formation (Fig. 5), while no obvious alteration in cell cycle progression analysis ( $p>0.05$, data not shown) and apoptosis evidenced by Annexin- $\mathrm{V}$ was observed ( $p>0.05$, data not shown).

\section{AKT mediates MAC30 inhibited proliferation}

MAC30 gene knockdown suppressed the growth of BGC-823 and AGS cell compared with that of the control-transfected ones (MOCK). To understand the underlying mechanism of 


\begin{tabular}{|c|c|c|}
\hline \multirow{2}{*}{$\begin{array}{l}\text { Cellular Physiology } \\
\text { and Biochemistry }\end{array}$} & \multirow{2}{*}{\multicolumn{2}{|c|}{$\begin{array}{l}\text { Cell Physiol Biochem 2014;33:1359-1368 } \\
\begin{array}{l|l}\text { DOI: } 10.1159 / 000358703 & \text { O 2014 S. Karger AG, Basel }\end{array}\end{array}$}} \\
\hline & & $\begin{array}{l}\text { O } 2014 \text { S. Karger AG, Basel } \\
\text { www.karger.com/cpb }\end{array}$ \\
\hline
\end{tabular}

Fig. 4. MAC30 siRNAtreated cells had a weaker ability to migrate and invade $(*, p<0.05)$. (A) MOCK: BGC-823 transfected with control siRNA; MAC30 siRNA: BGC823 transfected with MAC30 siRNA. (B) MOCK: AGS transfected with control siRNA; MAC30 siRNA: AGS transfected with MAC30 siRNA. Results are representative of three different experiments and data are expressed as mean $\pm \mathrm{SE}$.

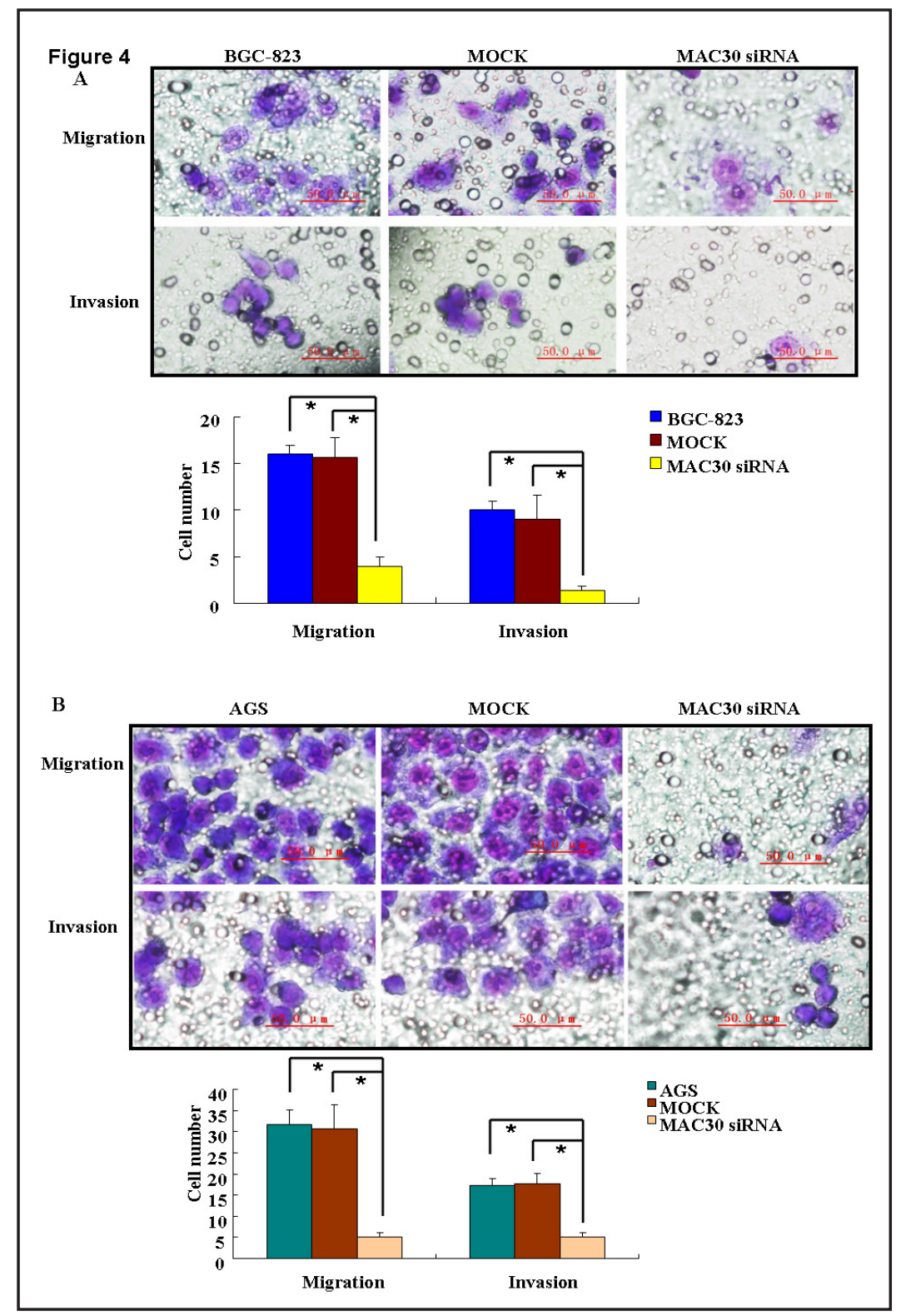

MAC30, we analyzed several potential genes. The phosphatidylinositol-3-kinase (PI3K)/Akt signaling plays a pivotal role in regulating cell proliferation [13]. We thus investigated whether the Akt pathway was involved in MAC30-knockdown inhibited-cell proliferation. By western blot analysis, we found that BGC-823 and AGS cells showed a decline of phosphorylated Akt1/2/3 (Ser473) after MAC30 siRNA transfection, and while phosphorylated Akt1/2/3 (Ser308) and the total Akt expression showed no obvious changes. Furthermore, we found that cyclinB1 protein levels decreased significantly with MAC30 knock-down in BGC-823 and AGS cells as compared with the control (Fig. 6).

MAC30 knockdown inhibits migration and invasion through down-regulation of WAVE2/ F-actin expression

To understand the cause of MAC30-inhibited mobility in BGC-823 cell, we analyzed two associated proteins, MMP2 and WAVE2. Expression of MMP2 protein has no significant change in MAC30-knockdown BGC-823 and AGS cells than the controls (Fig. 6). While MAC30-knockdown could down-regulate WAVE2 and F-actin expression involved in the lamellipodia formation in BGC-823 and AGS cells (Fig. 5 and 6). 
Fig. 5. After transfection of MAC30 siRNA, MAC30 expression was reduced in $\mathrm{BGC}-823$ and AGS cells by IF. MAC30 siRNAtreated showed weaker lamellipodia formation, labeled with Factin immunostaining. (A) MOCK: BGC-823 transfected with control SiRNA; MAC30 siRNA: BGC-823 transfected with MAC30 siRNA. (B) MOCK: AGS transfected with control siRNA; MAC30 siRNA: AGS transfected with MAC30 siRNA. Results are representative of three different experiments.

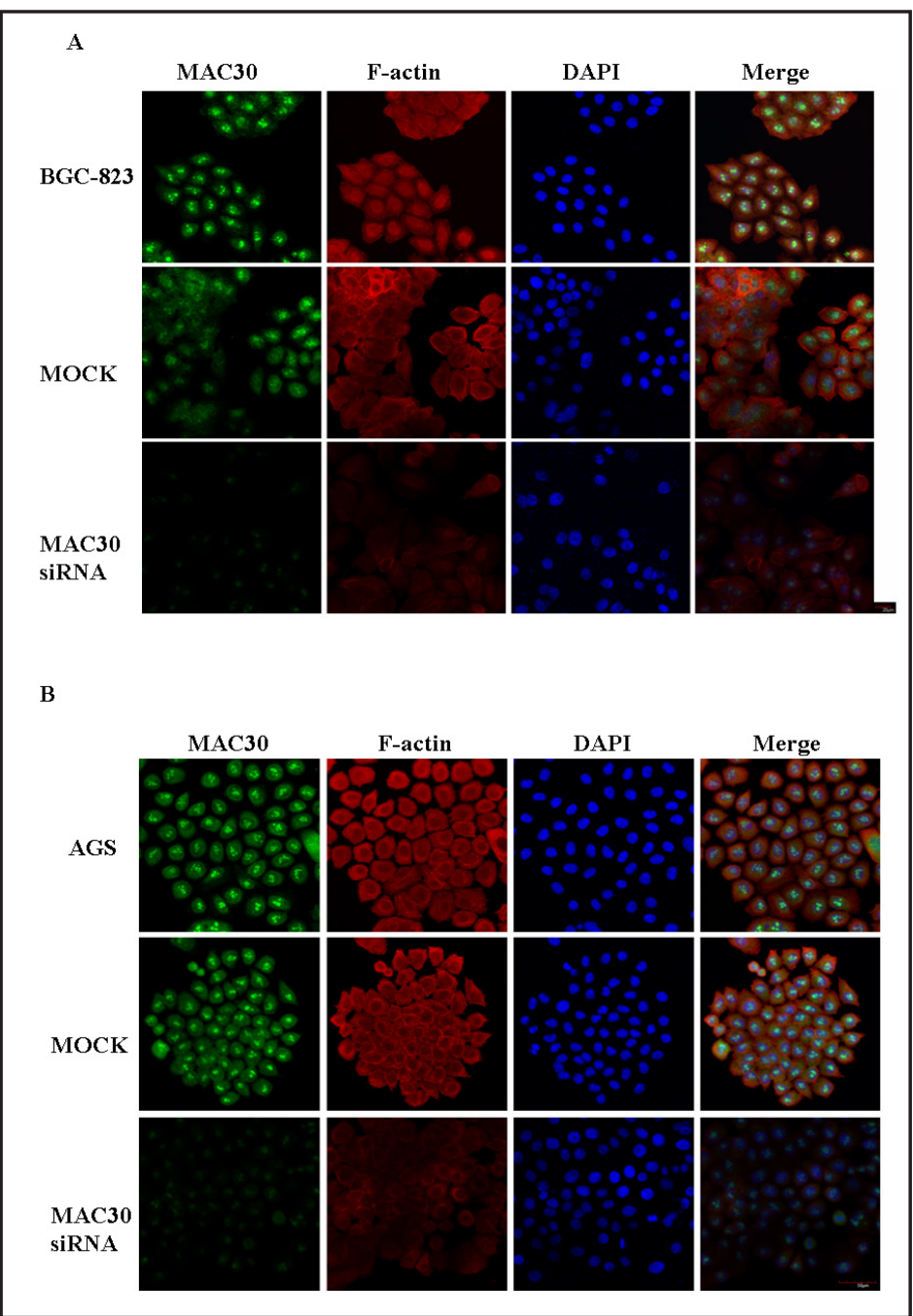

\section{Discussion}

Our data show that MAC30 is expressed in gastric carcinoma cell lines, and which is high in some gastric carcinoma cell lines, BGC-823 and AGS. Further, we have shown that MAC30 regulates proliferation, migration and invasion of BGC-823 and AGS cells through AKT and WAVE2. Our data suggest that MAC30 can function as a factor that promotes gastric carcinoma cells growth and movement.

The higher expression of MAC30 at the invasive margin of primary and metastatic tumor, suggests that MAC30 protein may play an important role in the development and aggressiveness of colorectal cancer [8]. Consistent with this report, esophageal, gastric and colon tumors displayed strong MAC30 immunoreactivity in the cancer cells [2, 3, 5]. The expression of MAC30 was remarkably elevated in colorectal cancer compared to the adjacent noncancerous and distant normal mucosa [14]. MAC30 up-regulation in certain tumors and down-regulation in others suggests that this protein plays a distinct role in human malignancies.

In our study, after transfected with MAC30 siRNA, MAC30 protein was significantly decreased in BGC-823 and AGS cells. The invasiveness of MAC30-knockdown BGC-823 and AGS cell lines was less than that of the negative control siRNA-transfected cell lines. Expression of WAVE2 protein was significantly lower in MAC30-knockdown BGC-823 and AGS cells than in control cells. Notably, the expression of MAC30 is important for gastric cancer progression. Consistent with other studies, the overexpression of MAC30 might be 


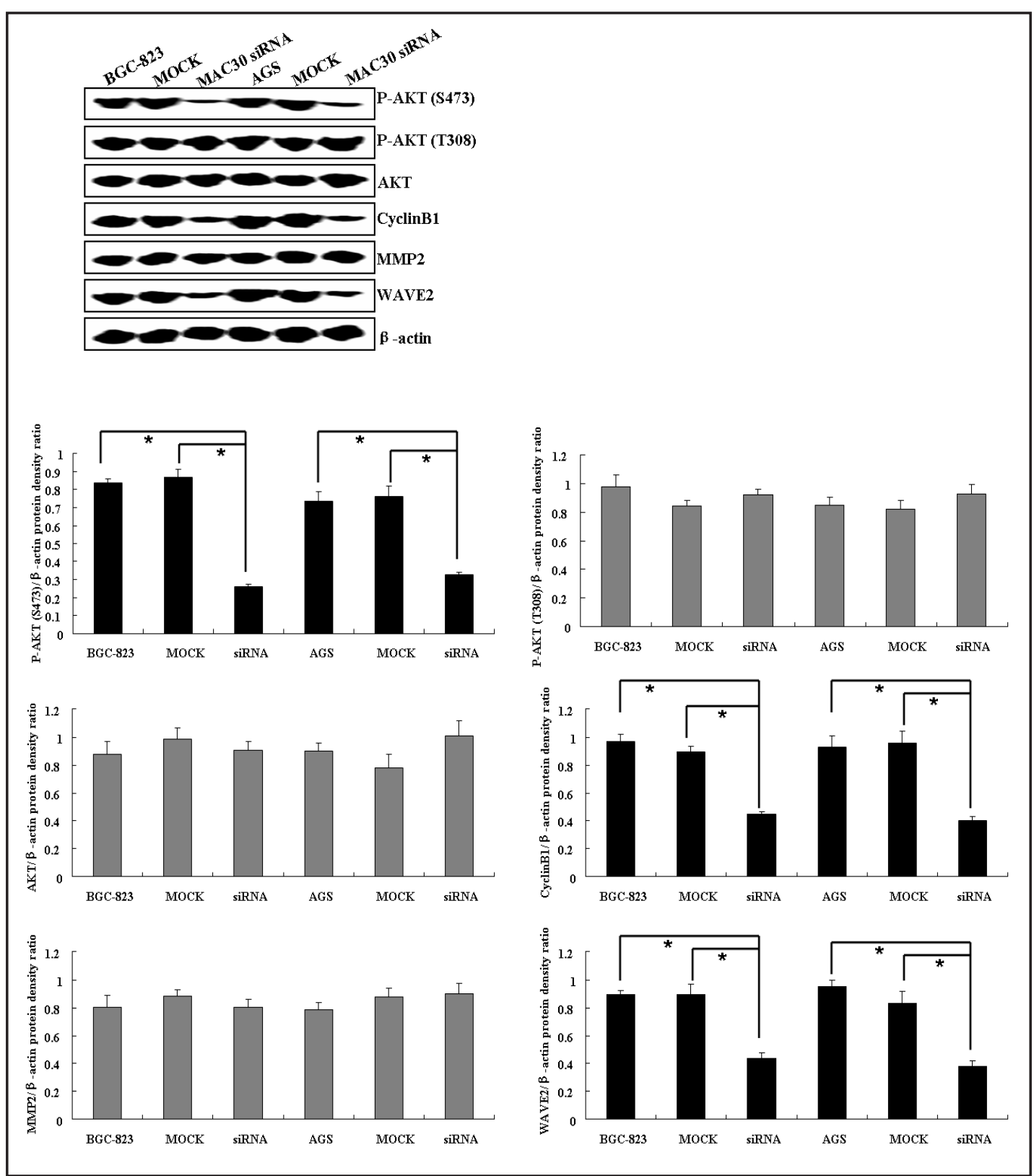

Fig. 6. Western blot showed protein expression between BGC-823 or AGS and transfectants in phosphorylated Akt1/2/3 Ser473 (60 kDa), Akt1/2/3 Thr308 (60 kDa), total Akt1/2/3 (60 kDa), cyclin B1 (48 $\mathrm{kDa}), \mathrm{MMP} 2 /(63 \mathrm{kDa})$, and WAVE2 (68 kDa). $\beta$-actin $(42 \mathrm{kDa})$ as an internal control. Protein expression of phosphorylated Akt1/2/3 Ser473, cyclin B1 and WAVE2 decreased in MAC30-knockdown BGC-823 and AGS cells than the controls $(*, p<0.05)$ Results are representative of three different experiments and data are expressed as mean \pm SE.

involved in the development and aggressiveness of colorectal cancer [14]. The overexpression of MAC30 was associated with tumor progression, recurrence, and poor survival in breast cancer [15]. The overexpression of MAC30 in the cytoplasm of oral squamous cell carcinoma may predict nodal metastasis and poor differentiation [11]. The overexpression of MAC30 in Non-small-cell lung cancer and associated with poor tumor differentiation, TNM stage, and lymph node metastasis, as well as poor prognosis of Non-small-cell lung cancer patients [16]. 
The phosphatidylinositol-3 kinase (PI3K)/Akt signaling represents a major cell survival pathway and its activation has long been associated with malignant transformation and apoptotic resistance [17]. Here, we found that the expression of phosphorylated Akt1/2/3 (Ser473) was reduced after MAC30 knockdown, which may have relation to the proliferation of gastric carcinoma cells.

CyclinB1 plays in integral role in many types of cancer. The cyclinB1/Cdk1 complex is the primary regulator of the transition from $G_{2}$ to $M$ phase [18]. Without synthesis of cyclinB1 before the $\mathrm{G}_{2} / \mathrm{M}$ transition, $\mathrm{Cdk} 1$ remains inactive, and the cell cannot enter mitosis, resulting in cell cycle arrest at the $G_{2}$ phase [19]. Our data suggest that MAC30 knockdown in BGC-823 and AGS cells had little influence on $\mathrm{G}_{2} / \mathrm{M}$ transition. However, the inhibitory effects of MAC30 on the suppressed growth in human gastric cells may be due to a reduction of cyclinB1 expression.

This study shows that the MAC30-knockdown could down-regulate WAVE2 and F-actin expression involved in the lamellipodia formation in BGC-823 and AGS cells. WAVE2 expression is elevated in human hepatocellular carcinoma, which correlates with a poor prognosis [20]. WAVE2 plays a critical role in actin-based processes downstream of Rac that are essential for cell movement in murine embryogenesis [21]. WAVE2 has previously been shown to be essential for the migration and invasion of mouse melanoma cells [22]. In addition, enhancement of WAVE2 expression facilitates the invasion of breast cancer cell line MDA-MB-231 [23]. Recently, Yao et al. found that WAVE2 was overexpressed in gastric cancer cells and there was a significant correlation between WAVE2 protein levels and the migration/invasion of gastric cancer cell lines [24]. Our previous results showed that REIC (Reduced Expression in Immortalized Cells) overexpression or recombinant REIC treated suppressed invasion and metastasis of gastric carcinoma cell line AGS through the downregulation of WAVE2 [25].

In conclusion, we have shown that aberrant expression of MAC30 might play important roles in growth, migration and invasion of gastric carcinoma cells. We also demonstrated that MAC30 increased cell proliferation via trans-activation of Akt pathway. More importantly, we provided clear evidence that MAC30 enhances the migration and invasion of gastric cancer cells via WAVE2. Our work provides strong evidence suggesting that MAC30 is a potential therapeutic target of human gastric cancers, which may represent an attractive novel adjunct to current chemotherapy.

\section{Acknowledgements}

This study was supported by Shenyang Science and Technology Grant (F12-277-175); National Natural Scientific Foundation of China (No.81001093); a Project Supported by Scientific Research Fund of Liaoning Provincial Education Department (No. L2010649) and Specialized Research Fund for the Doctoral Program of Higher Education (No. 20102104120026); National College Students' Innovation Training Project (201310159057). We thank Dr. Pu Xia for his valuable comments and excellent technical assistance.

\section{References}

1 Kelley JR, Duggan JM: Gastric cancer epidemiology and risk factors. J Clin Epidemiol 2003;56:1-9.

2 Murphy M, Pykett MJ, Harnish P, Zang KD, George DL: Identification and characterization of genes differentially expressed in meningiomas. Cell Growth Differ 1993;4:715-722.

3 Kayed H, Kleeff J, Ding J, Hammer J, Giese T, Zentgraf H, Buchler MW, Friess H: Expression analysis of MAC30 in human pancreatic cancer and tumors of the gastrointestinal tract. Histol Histopathol 2004;19:1021-1031.

-4 Bartz F, Kern L, Erz D, Zhu M, Gilbert D, Meinhof T, Wirkner U, Erfle H, Muckenthaler M, Pepperkok R, Runz $\mathrm{H}$ : Identification of cholesterol-regulating genes by targeted RNAi screening. Cell Metab 2009;10:63-75. 
-5 Wilcox CB, Feddes GO, Willett-Brozick JE, Hsu LC, DeLoia JA, Baysal BE: Coordinate up-regulation of TMEM97 and cholesterol biosynthesis genes in normal ovarian surface epithelial cells treated with progesterone: implications for pathogenesis of ovarian cancer. BMC Cancer 2007;7:223.

-6 Malhotra K, Luehrsen KR, Costello LL, Raich TJ, Sim K, Foltz L, Davidson S, Xu H, Chen A, Yamanishi DT, Lindemann GW, Cain CA, Madlansacay MR, Hashima SM, Pham TL, Mahoney W, Schueler PA: Identification of differentially expressed mRNAs in human fetal liver across gestation. Nucleic Acids Res 1999;27:839847.

7 Zhang ZY, Zhao ZR, Adell G, Jarlsfelt I, Cui YX, Kayed H, Kleeff J, Wang MW, Sun XF: Expression of MAC30 in rectal cancers with or without preoperative radiotherapy. Oncology 2006;71:259-265.

8 Moparthi SB, Arbman G, Wallin A, Kayed H, Kleeff J, Zentgraf H, Sun XF: Expression of MAC30 protein is related to survival and biological variables in primary and metastatic colorectal cancers. Int J Oncol 2007;30:91-95.

-9 Yang S, Li H, Liu Y, Ning X, Meng F, Xiao M, Wang D, Lou G, Zhang Y: Elevated expression of MAC30 predicts lymph node metastasis and unfavorable prognosis in patients with epithelial ovarian cancer. Med Oncol 2013;30:324.

10 Han KY, Gu X, Wang HR, Liu D, Lv FZ, Li JN: Overexpression of MAC30 is associated with poor clinical outcome in human non-small-cell lung cancer. Tumour Biol 2012;34:821-825.

11 Yan BY, Wang DW, Zhu ZL, Yang YH, Wang MW, Cui DS, Zhang H, Sun XF: Overexpression of MAC30 in the cytoplasm of oral squamous cell carcinoma predicts nodal metastasis and poor differentiation. Chemotherapy 2010;56:424-428.

12 Hammill AK, Uhr JW, Scheuermann RH: Annexin V staining due to loss of membrane asymmetry can be reversible and precede commitment to apoptotic death. Exp Cell Res 1999;251:16-21.

13 Ma J, Sawai H, Ochi N, Matsuo Y, Xu D, Yasuda A, Takahashi H, Wakasugi T, Takeyama H: PTEN regulates angiogenesis through PI3K/Akt/VEGF signaling pathway in human pancreatic cancer cells. Mol Cell Biochem 2009;331:161-171.

-14 Zhao ZR, Zhang LJ, He XQ, Zhang ZY, Zhang F, Li F, Pei YB, Hu YM, Wang MW, Sun XF: Significance of mRNA and protein expression of MAC30 in progression of colorectal cancer. Chemotherapy 2011;57:394-401.

15 Xiao M, Li H, Yang S, Huang Y, Jia S, Wang H, Wang J, Li Z: Expression of MAC30 protein is related to survival and clinicopathological variables in breast cancer. J Surg Oncol 2012;107.

16 Han KY, Gu X, Wang HR, Liu D, Lv FZ, Li JN: Overexpression of MAC30 is associated with poor clinical outcome in human non-small-cell lung cancer. Tumour Biol 2013;34:821-825.

17 Vivanco I, Sawyers CL: The phosphatidylinositol 3-Kinase AKT pathway in human cancer. Nat Rev Cancer 2002;2:489-501.

18 Xu XY, Zhang Z, Su WH, Zhang Y, Feng C, Zhao HM, Zong ZH, Cui C, Yu BZ: Involvement of the p110 alpha isoform of PI3K in early development of mouse embryos. Mol Reprod Dev 2009;76:389-398.

19 Guadagno TM, Newport JW: Cdk2 kinase is required for entry into mitosis as a positive regulator of Cdc2cyclin B kinase activity. Cell 1996;84:73-82.

20 Yang LY, Tao YM, Ou DP, Wang W, Chang ZG, Wu F: Increased expression of Wiskott-Aldrich syndrome protein family verprolin-homologous protein 2 correlated with poor prognosis of hepatocellular carcinoma. Clin Cancer Res 2006;12:5673-5679.

21 Yan C, Martinez-Quiles N, Eden S, Shibata T, Takeshima F, Shinkura R, Fujiwara Y, Bronson R, Snapper SB, Kirschner MW, Geha R, Rosen FS, Alt FW: WAVE2 deficiency reveals distinct roles in embryogenesis and Rac-mediated actin-based motility. Embo J 2003;22:3602-3612.

22 Kurisu S, Suetsugu S, Yamazaki D, Yamaguchi H, Takenawa T: Rac-WAVE2 signaling is involved in the invasive and metastatic phenotypes of murine melanoma cells. Oncogene 2005;24:1309-1319.

23 Yokotsuka M, Iwaya K, Saito T, Pandiella A, Tsuboi R, Kohno N, Matsubara O, Mukai K: Overexpression of HER2 signaling to WAVE2-Arp2/3 complex activates MMP-independent migration in breast cancer. Breast Cancer Res Treat 2011;126:311-318.

24 Yao Q, Cao Z, Tu C, Zhao Y, Liu H, Zhang S: MicroRNA-146a acts as a metastasis suppressor in gastric cancer by targeting WASF2. Cancer Lett 2013;335:219-224.

-25 Xu XY, Xia P, Yu M, Nie XC, Yang X, Xing YN, Liu YP, Takano Y, Zheng HC: The roles of REIC gene and its encoding product in gastric carcinoma. Cell Cycle 2012;11:1414-1431. 